\title{
Numerical Research of Fracture Toughness of Aged Ferritic-Martensitic Steel
}

\author{
Remigijus Janulionis ${ }^{1}(\mathbb{D})$, Gintautas Dundulis ${ }^{1,2, *(\mathbb{D})}$ and Albertas Grybènas ${ }^{3}$ \\ 1 Laboratory of Nuclear Installation Safety, Lithuanian Energy Institute, Breslaujos str. 3, \\ LT-44403 Kaunas, Lithuania; remigijus.janulionis@lei.lt \\ 2 Department of Mechanical Engineering, Faculty of Mechanical Engineering and Design, \\ Kaunas University of Technology, Studentu str. 56, LT-51424 Kaunas, Lithuania \\ 3 Laboratory of Material Research and Testing, Lithuanian Energy Institute, Breslaujos str. 3, \\ LT-44403 Kaunas, Lithuania; albertas.grybenas@lei.lt \\ * Correspondence: gintautas.dundulis@lei.lt; Tel.: +370-37-401918
}

Received: 30 October 2020; Accepted: 12 December 2020; Published: 17 December 2020

\begin{abstract}
Generally, material properties such as the modulus of elasticity, yield strength or fracture toughness are determined by conducting an experiment. Sometimes experimental determination cannot be done due to specific experimental conditions, lack of testing material and so on. Also, experiments are time consuming and costly. Therefore, there arises the need for alternative determination methods. A numerical method for the fracture toughness determination of steel P91 is suggested in this paper. For this purpose, the universal finite element software ABAQUS was used. The numerical simulation of the $C(T)$ specimen tension test was carried out using non-linear simulation for a conditional load $P_{Q}$ determination, and linear simulation for fracture toughness value $K_{Q}$ determination. The suggested method is validated by comparing numerical and experimental tests results. The secondary aim of the paper is the evaluation of the ageing effect on the fracture toughness of steel P91. Thermal ageing of the steel was carried out in an electric furnace at $650{ }^{\circ} \mathrm{C}$ up to $11,000 \mathrm{~h}$. As the numerical results had a good coincidence with experimental data at room temperature, the prediction of fracture toughness at elevated temperature, i.e., $550{ }^{\circ} \mathrm{C}$, using numerical method was carried out.
\end{abstract}

Keywords: fracture toughness; ageing; experimental testing of material; finite element method; steel P91

\section{Introduction}

For the prediction of the lifetime of construction or its components the ageing of the materials has to be taken into account. Various ageing mechanisms such as corrosion, fatigue and others can significantly reduce material capability to withstand an applied load by reducing its mechanical properties, i.e., tensile strength, yield strength, ductility, etc. Also, small defects, which appear in manufacturing process, can grow into cracks that could cause a component failure. The understanding of how ageing affects material resistance to cracking is important. Fracture toughness $\left(K_{I C}\right)$ [1] is the property which describes the ability of material to resist fracture. It has an important role in the fracture mechanics since it characterizes the stress field in the crack tip region, and helps to predict the fracture condition and remaining lifetime of a mechanical component with cracks [2]. It is a material property where different materials have a different value which depends on the environment, i.e., temperature [3] etc. Various standards such as ASTM and ISO describe the procedures for experimental determination of $K_{I C}$. Sometimes experimental $K_{I C}$ determination cannot be done due to specific experimental conditions, such as lack of testing material and so on. Also, experiments are time 
consuming and costly. Therefore, there is a need for alternative $K_{I C}$ determination methods. This paper presents the methodology for numerical determination of fracture toughness, which is validated by experimental tests.

The finite element method (FEM) is the most widely used numerical method for fracture toughness and stress intensity factor (SIF) evaluation. Zare et al. [2] used the finite element method to calculate the stress intensity factor in the finite plate with an edge crack under uniaxial stress loading. It was showed that the neural network method should be used to predict the correlation of the SIF and the position of the edge crack along the length of a finite plate. The specimen size effect related to fracture toughness was investigated by Sakib and Adnan [4]. However, Sakib and Adnan presented the methodology for nanoscale specimens. The authors of the papers $[5,6]$ deal with determination of the SIF using the finite element method and compare simulated results with the theoretical solution. The analysis shows that the numerical solution using the finite element method is more suitable than the analytical solution, because the analytical equations are limited in a range of parameters values; some parameters, such as plate length, are not considered and also it is difficult to determine the accurate SIF for cracks in complex structures. According to the good potential of FEM in fracture mechanics applications it was chosen as the numerical method for fracture toughness determination in this paper.

For the research object as-received and aged ferritic-martensitic steel P91 were chosen. Steel P91 was developed based on 1960s steels with $12 \% \mathrm{Cr}$ content. $12 \% \mathrm{Cr}$ content steel has a creep problem when it is exposed at higher temperatures and pressures, the conditions typically experienced at power plants, where temperatures can reach $565^{\circ} \mathrm{C}$. Therefore, steel with increased creep resistance, i.e., steel P91, was developed by the Oak Ridge National Laboratory in Tennessee, USA; it consists of $9 \% \mathrm{Cr}$ and $1 \%$ Mo [7]. P91 has a tempered martensite structure after austenitization, air cooling and tempering [8]. At present, steel P91 is widely used in boiler components of ultra-supercritical power plants; also it is a common choice of pipe material for heat exchangers in nuclear power plants [9].

The main aim of this research is to present and validate the numerical method for the fracture toughness determination. The validation of the numerical determination methodology was done by comparing the obtained fracture toughness values with the values determined experimentally. As the secondary aim of the research is to investigate the ageing effect on fracture toughness of steel P91. For this purpose, ageing of the steel was performed in laboratory conditions at $650{ }^{\circ} \mathrm{C}$ for different durations and up to 11,000 h. Experimental evaluation of fracture toughness for the validation of the numerical method was done at room temperature. As the numerical results had a good coincidence with experimental results, the prediction of fracture toughness at elevated temperature, i.e., $550{ }^{\circ} \mathrm{C}$, using numerical method was carried out. Steel P91 is being considered as a structural material in the fourth-generation reactors and fusion power plants due to its good thermo-physical properties, excellent stability under irradiation and good creep strength up to $550^{\circ} \mathrm{C}$. An elevated temperature of $550^{\circ} \mathrm{C}$ was selected because it is designed to be an operational temperature of coolant in IV generation sodium cooled nuclear reactors [10].

\section{Experimental Research of Steel P91}

\subsection{Material and Long-Term Ageing}

Steel plate of $30 \mathrm{~mm}$ thickness and made of steel P91 was received for experimental testing. A metal analyser Q4 Tasman was used for determination of chemical composition of the as-received sample. These results are presented in Table 1.

Table 1. Chemical composition of the as-received P91 steel plate (wt.\%).

\begin{tabular}{ccccccccccccc}
\hline $\mathbf{C}$ & $\mathbf{S i}$ & $\mathbf{M n}$ & $\mathbf{P}$ & $\mathbf{S}$ & $\mathbf{N}$ & $\mathbf{A l}$ & $\mathbf{C r}$ & $\mathbf{M o}$ & $\mathbf{C u}$ & $\mathbf{N b}$ & $\mathbf{N i}$ & $\mathbf{V}$ \\
\hline 0.094 & 0.38 & 0.35 & 0.006 & $<0.0005$ & 0.035 & 0.012 & 8.78 & 0.96 & 0.07 & 0.08 & 0.16 & 0.18 \\
\hline
\end{tabular}


The steel plate was cut into smaller samples. The samples were placed in steel boxes filled with calcium carbonate powder to minimize oxidation and isothermally annealed in an electric furnace at $650{ }^{\circ} \mathrm{C}$. The ageing durations were 790, 4150 and 11,000 h. Later, aged steel samples were used for manufacturing of specimens for tensile and fracture toughness testing. The microstructures of P91 steel and its changes after ageing are presented in Figure 1. The figure shows that thermal ageing does have an influence on the microstructure of steel P91. The precipitates do increase in size and continuously degrade the material. Precipitates were observed at the grain boundaries as well as inside the ferrite grains. Coarsening was also noticed at longer ageing times. During ageing $\mathrm{Cr}$ and Mo partly replace Fe atoms in the M23C6 carbide lattice. Cr atoms dominate in the M23C6 carbide lattice, because Cr has a higher diffusion coefficient than Mo [11,12]; this was confirmed in previous research [13] where EDX analysis of extracted residue from steel P91 was done.

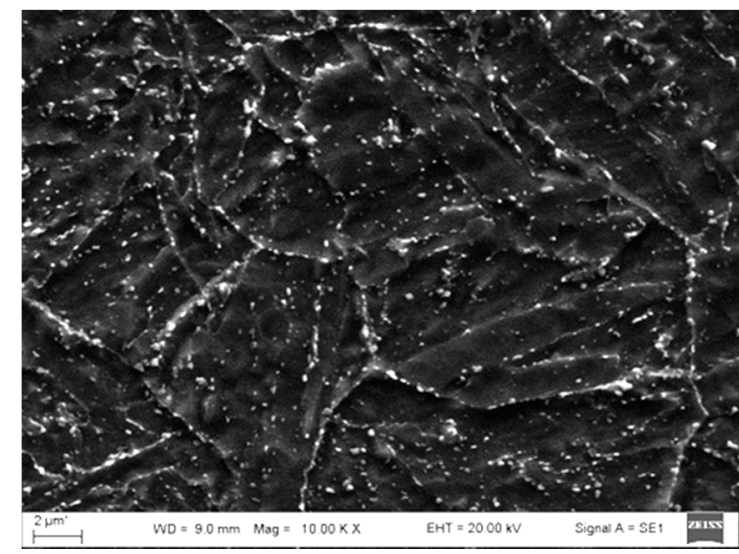

(a)

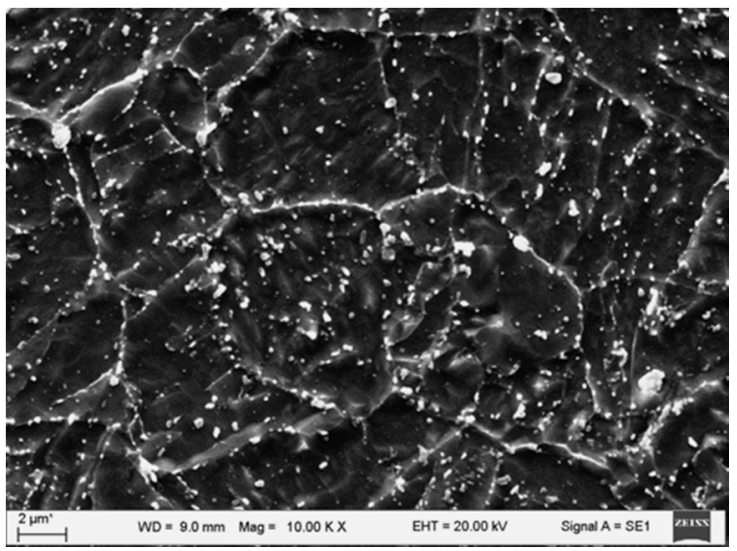

(b)

Figure 1. SEM (CARL ZEISS MICROSCOPY LIMITED, Cambridge, UK) microstructure of the P91 steel in the as-received condition (a) and after $11,000 \mathrm{~h}$ of ageing at $650{ }^{\circ} \mathrm{C}(\mathbf{b})$.

\subsection{Experimental Research Methodology}

An Instron Model 8801 test machine (Instron limited, Buckinghamshire, UK) was used for testing the mechanical properties and fracture toughness of steel P91. Room temperature tensile tests were carried out according to EN ISO 6892-1 [14] requirements and elevated temperature tests were carried out according to EN ISO 6892-2 [15] requirements. The cylindrical specimens with a threaded shoulder were selected for this research. The diameter of specimens for the testing was $8 \mathrm{~mm}$ and gauge length was $40 \mathrm{~mm}$. The fracture toughness experiments were carried out according to the ASTM E399 [16] standard. The compact tension C(T) specimens were selected for this purpose. The drawing of manufactured specimens for fracture toughness testing is shown in Figure 2.

All experimental tests results are presented in Section 4.1. 


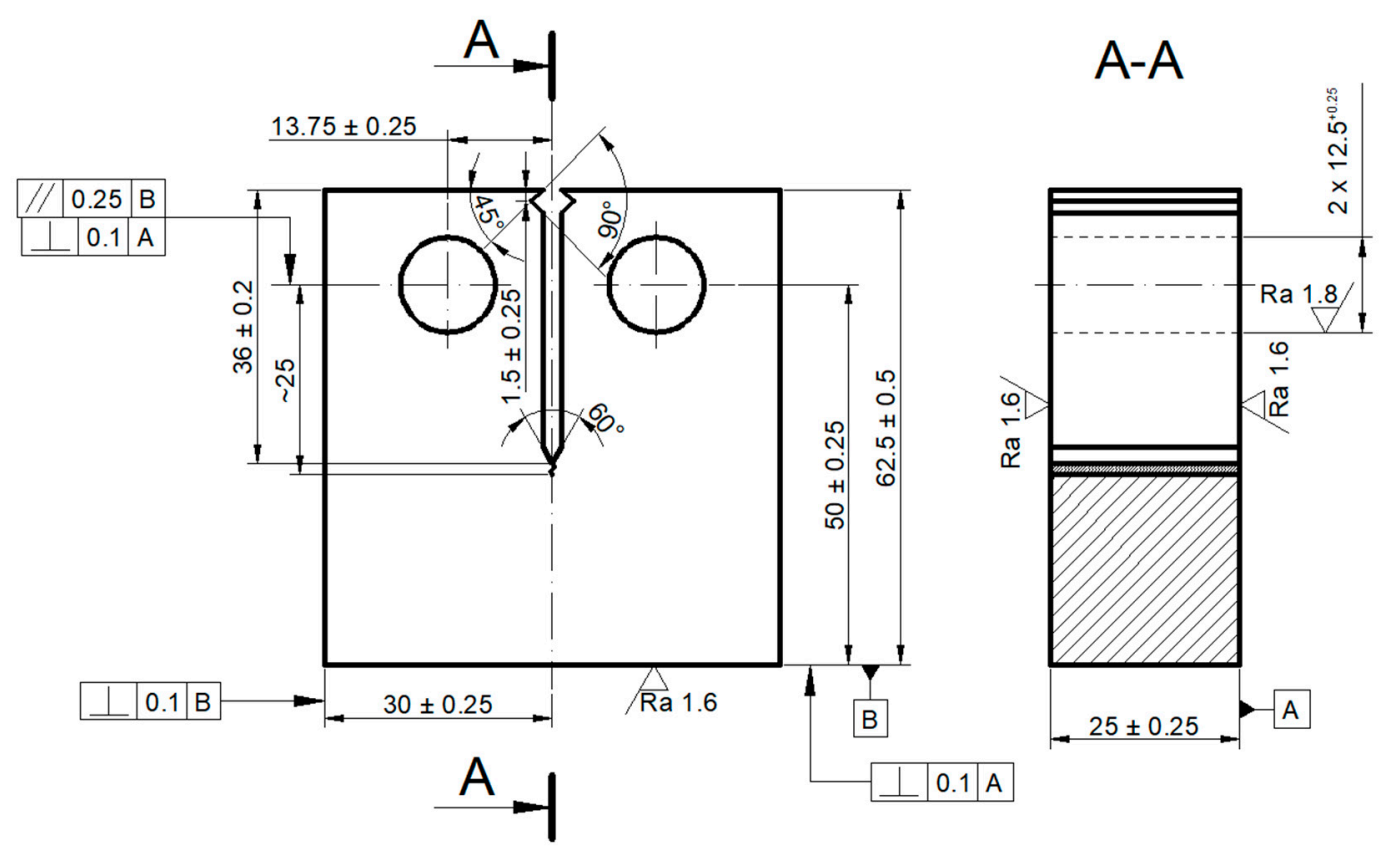

Figure 2. C(T) specimen drawing (dimensions are in mm), according to the ASTM E 399 standard [16].

\section{Numerical Simulation of Fracture Toughness}

\subsection{Methodology of the Numerical Simulation of Fracture Toughness}

The numerical research of fracture toughness was done by numerically simulating experimental tests according to the ASTM E 399 standard.

To determine fracture toughness $K_{I C}$, at first, the so-called conditional stress intensity factor value $K_{Q}$ has to be found. Then, if all requirements and conditions described in the ASTM E399 standard are met, it can be stated that $K_{Q}=K_{I C}$. First of all, load vs. crack mouth opening displacement (CMOD) has to be created for $K_{Q}$ determination. Experimentally, $C M O D$ is measured using a shoulder extensometer (Instron limited, Buckinghamshire, UK) placed in machined $90^{\circ} \mathrm{V}$-shaped notches at the end of the specimen (see Figure 2). In numerical modelling, the CMOD can be determined by tracking the displacement of the notch edge. A constructed curve is used for determination of loads $P_{Q}$ and $P_{\max } . P_{\max }$ is the load value at the highest load point of the curve. $P_{Q}$ is the load at which the SIF reaches the $K_{Q}$ value. For this purpose, additional lines must be drawn. The OA line is a tangent line to the linear part of the curve (see Figure 3), where point $\mathrm{O}$ is at the origin of the curve. Line $\mathrm{OP}_{5}$ is a secant line with a $5 \%$ slope to the OA line and found by $(P / v)_{5}=0.95(P / v)_{O}$. In the case of a Type I curve, $P_{Q}$ is found at the intersection point of the curve and the secant line. For Type II and Type III curves, the $P_{Q}$ load is found at the first vertex.

Knowing the $P_{Q}$ load, $K_{Q}$ can be analytically calculated by using the following equation for a standard $\mathrm{C}(\mathrm{T})$ specimen [16]:

$$
K_{Q}=\left(P_{Q} / B W^{1 / 2}\right) \cdot f(a / W)
$$

where:

$$
f(a / W)=\frac{\left(2+\frac{a}{W}\right)}{\left(1-\frac{a}{W}\right)^{3 / 2}} \cdot\left[0.886+4.64 \frac{a}{W}-13.32\left(\frac{a}{W}\right)^{2}+14.72\left(\frac{a}{W}\right)^{3}-5.6\left(\frac{a}{W}\right)^{4}\right],
$$

where $P_{Q}$ is the load at which $K_{Q}$ is found, N; $B$ is the thickness of the specimen (see Figure 4), m; $W$ is the width of the specimen (see Figure 4), m; $a$ is the length of the crack (see Figure 4), $m$. 


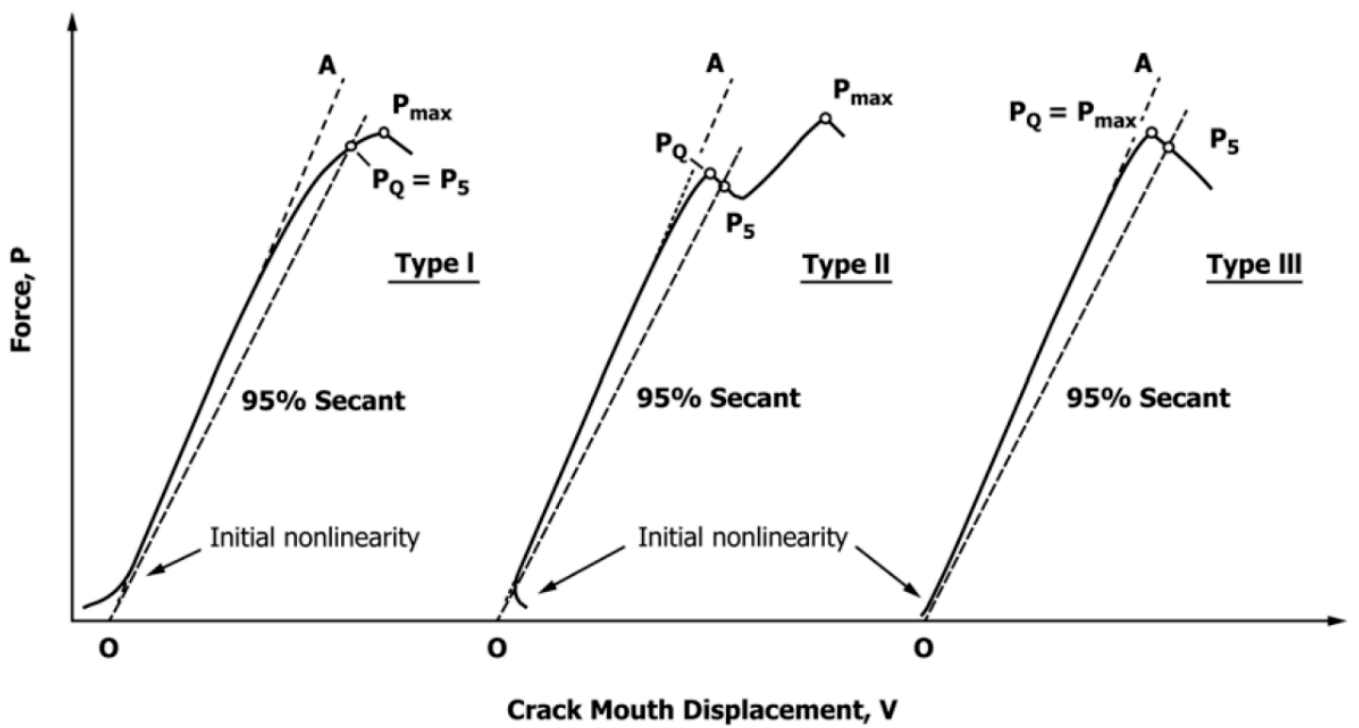

Figure 3. Principal types of force-displacement (CMOD) records (ASTM E399-12e3 2012).

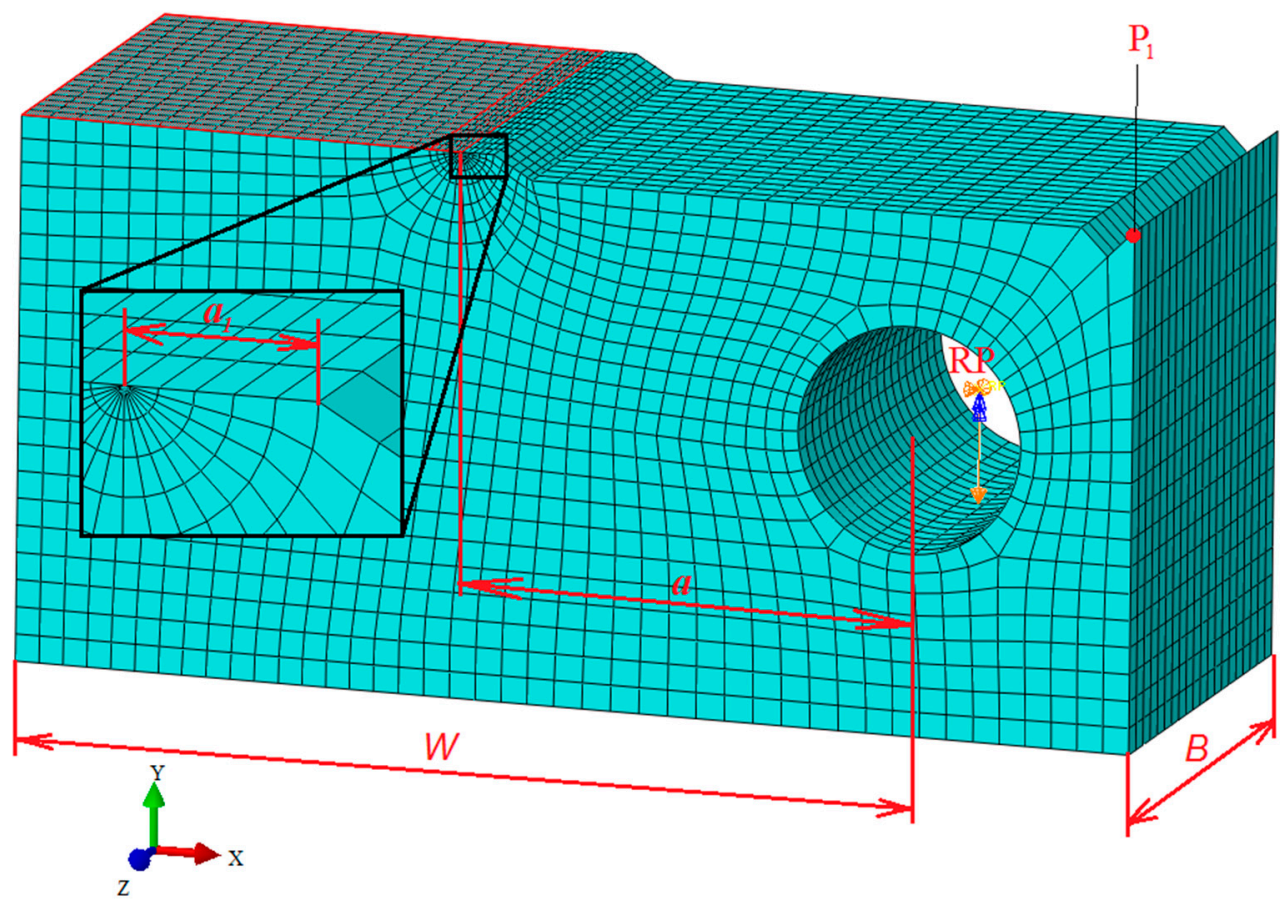

Figure 4. Finite element mesh of the $\mathrm{C}(\mathrm{T})$ specimen.

$K_{\max }$ is calculated using the same Equations (1) and (2) as for the $K_{Q}$ calculation, only replacing load $P_{Q}$ with load $P_{\max }$.

Numerical simulation of fracture toughness was thus done by applying the instructions described above to the finite element model. ABAQUS v6.11 [17] was chosen as the finite element code. The influence of the ageing effect of steel P91 was evaluated by applying material properties of aged steel (see Figure 5 and Table 2) in the FE model. 


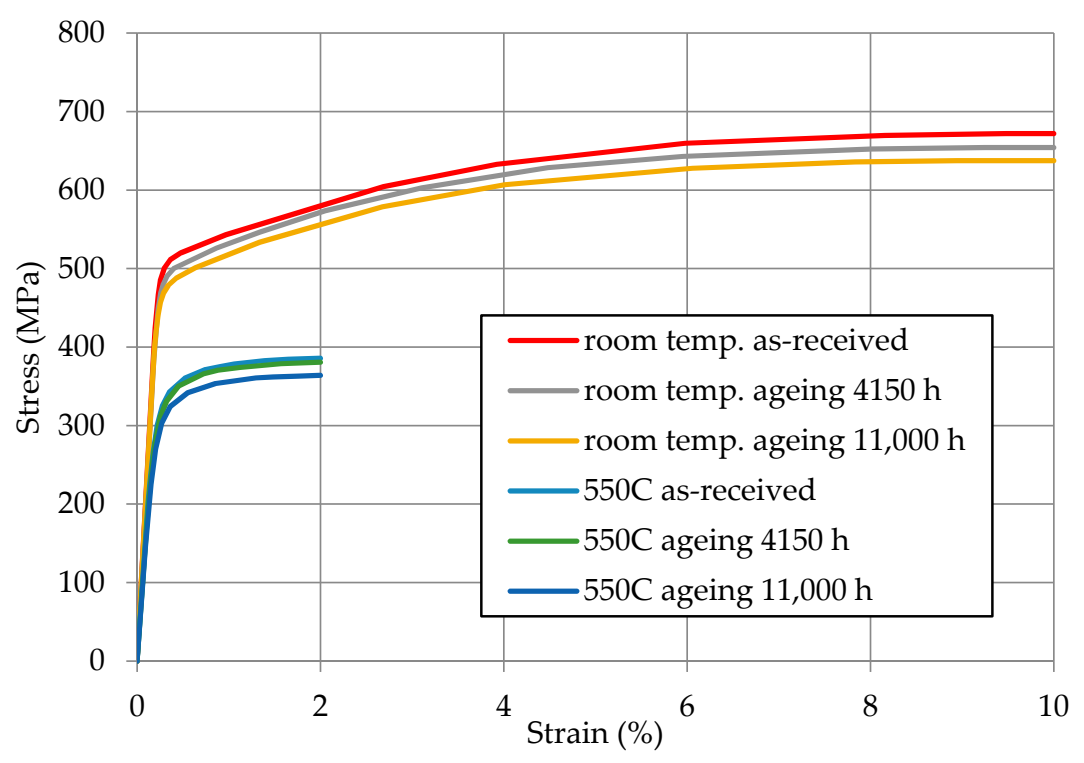

Figure 5. Stress-strain curves of the as-received and aged steel P91 at room and elevated temperatures.

Table 2. Mechanical properties of the P91 steel plate.

\begin{tabular}{ccccccc}
\hline $\begin{array}{c}\text { Test Temperature } \\
\left({ }^{\circ} \mathbf{C}\right)\end{array}$ & $\begin{array}{c}\text { Ageing Time at } \\
\mathbf{6 5 0}{ }^{\circ} \mathbf{C}(\mathbf{h})\end{array}$ & $\boldsymbol{R}_{\mathbf{p}} \mathbf{( M P a )}$ & $\left.\boldsymbol{R}_{\mathbf{m}} \mathbf{( M P a}\right)$ & $\boldsymbol{A}_{\mathbf{g t}}(\mathbf{\%})$ & $\boldsymbol{A}_{\mathbf{t}}(\mathbf{\%})$ & $\mathbf{E}(\mathbf{G P a})$ \\
\hline & 0 & 513 & 666 & 9.8 & 23 & 214 \\
Room temperature & 790 & 507 & 658 & 9.9 & 23 & 212 \\
& 4150 & 501 & 651 & 9.5 & 22 & 212 \\
& 11,000 & 487 & 637 & 9.2 & 21 & 209 \\
550 & 0 & 350 & 385 & 2.0 & 27 & 166 \\
& 790 & 350 & 388 & 2.5 & 27 & 165 \\
& 4150 & 349 & 381 & 2.0 & 28 & 165 \\
& 11,000 & 337 & 367 & 2.0 & 28 & 162 \\
\hline
\end{tabular}

\subsection{Numerical Model}

The FE model of a $\mathrm{C}(\mathrm{T})$ specimen was created for numerical simulation of fracture toughness using finite element code ABAQUS v6.11 (Dassault Systèmes Simulia Corp, Johnston, RI, USA). The mesh of the model is shown in Figure 4. As the specimen is symmetric, in order to reduce the modelling and computational efforts, only one half of it was created. All dimensions of the numerical model correspond to the dimensions of the specimen used in the experiment (see Figure 2). C3D20R elements [17] were chosen for the FE mesh. These elements are three-dimensional, brick-shaped and they have 20 nodes. Fatigue crack length $a_{1}$ (see Figure 4) was used for all numerical simulation cases and was equal to $1.8 \mathrm{~mm}$. To describe the material of the model, the mechanical properties, presented in Section 4.1, were applied. The elastic-plastic material behaviour was described by using the stress-strain curves determined experimentally (see Figure 5). The actual values were entered up to the limit of $A_{\mathrm{gt}}$ (see Table 2). The Poisson's coefficient of $v=0.3$ was used in all cases.

Reference points (RPs), which were placed in the centre of the pin hole of the specimen model, was used for the boundary conditions. The displacement along $\mathrm{X}$ and $\mathrm{Z}$ axis and rotation around the $\mathrm{Y}$ axis were restricted for the RP point. However, the translation of the RP point along the $\mathrm{Y}$ axis was used as a load. In order to evaluate large strains at the front of the crack the option for nonlinear geometric effects Nlgeom [17] was selected. The numerical model has yielded the following results: reaction force at the RP point, crack mouth opening displacement (CMOD), stress intensity factor and J-integral at the crack front. CMOD was measured by tracking the position of point $\mathrm{P}_{1}$ (see Figure 4) in the $\mathrm{Y}$ direction (point $\mathrm{P}_{1}$ is situated on the specimen edge where an extensometer is attached in the experiment). 
According to the user's manual [17] the mesh around the crack tip should be created in a particular shape. The elements should be brick shaped but they have to be laid out in a circular pattern around the crack. It is possible to make the mesh like this by collapsing the element's face nodes, which are the closest to the crack front, into the single line. That action makes prism shape elements which still have 20 nodes (see Figure 4). These types of elements are called singular elements.

\subsection{Numerical Determination of SIF}

As described in the methodology (see Section 3.1) tension load vs. CMOD curves were determined after simulation. Non-linear tension simulation with elastic-plastic material properties was used for this purpose. The comparison of experimental and numerical simulation results for not aged material at $20{ }^{\circ} \mathrm{C}$ is presented in Figure 6. The figure shows three experimentally determined curves and a curve determined by numerical simulation. As can be seen, experimental results are very close. According to Figure 6 the numerically determined curve quite well matches the curves determined experimentally, where the highest deviation of results is less than $5 \%$.

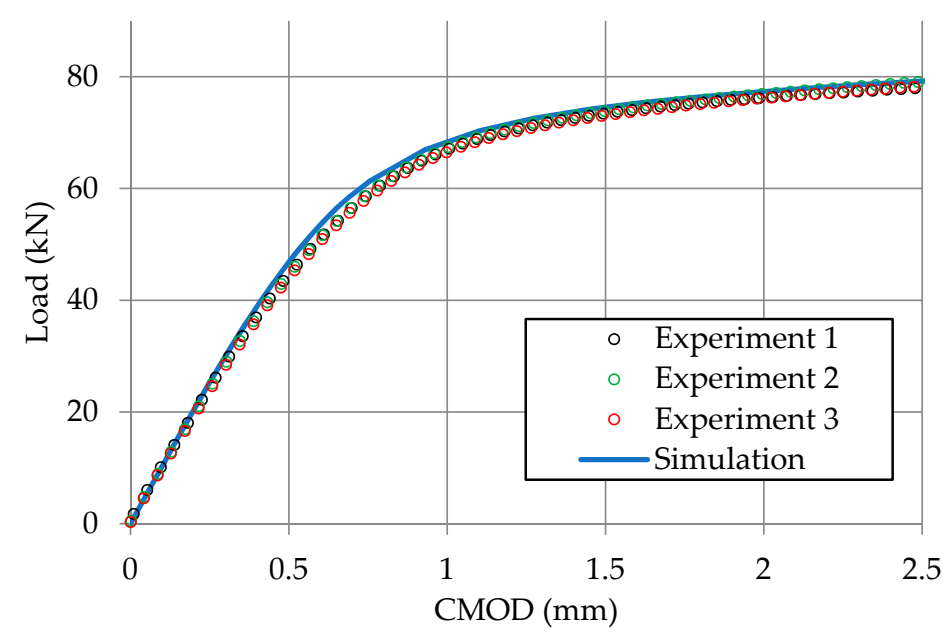

Figure 6. Experimentally and numerically determined tension load vs. CMOD curves for as-received steel P91 at room temperature.

When the load vs. CMOD curves are determined $P_{Q}$ and $P_{\max }$ loads can be found. These loads were determined using ASTM E399 procedures [16] as described in Section 3.1. As an example, the determination of the $P_{Q}$ load for not aged steel at room temperature is shown in Figure 7.

According to the ASTM E399 procedures [16] load $P_{Q}$ can be used for $K_{Q}$ determination. For this purpose, the load vs. stress intensity factor curve has to be constructed. The stress intensity factor can be calculated analytically or numerically. To calculate the SIF analytically the Equations (1) and (2) presented in Section 3.1 are used. Numerically, the stress intensity factor can be calculated by running the linear simulation of $\mathrm{C}(\mathrm{T})$ specimen tension. The other quite common way to calculate the SIF is by determination of the J-integral and recalculation of the SIF from the relation between $J$ and $K$ under plane strain condition. The stress intensity factor $K_{J}$ obtained from the J-integral can be found by equation:

$$
K_{J}=\sqrt{\frac{E J}{1-v^{2}}},
$$

where $E$ is the modulus of elasticity, Pa and $v$ is Poisson's ratio. 


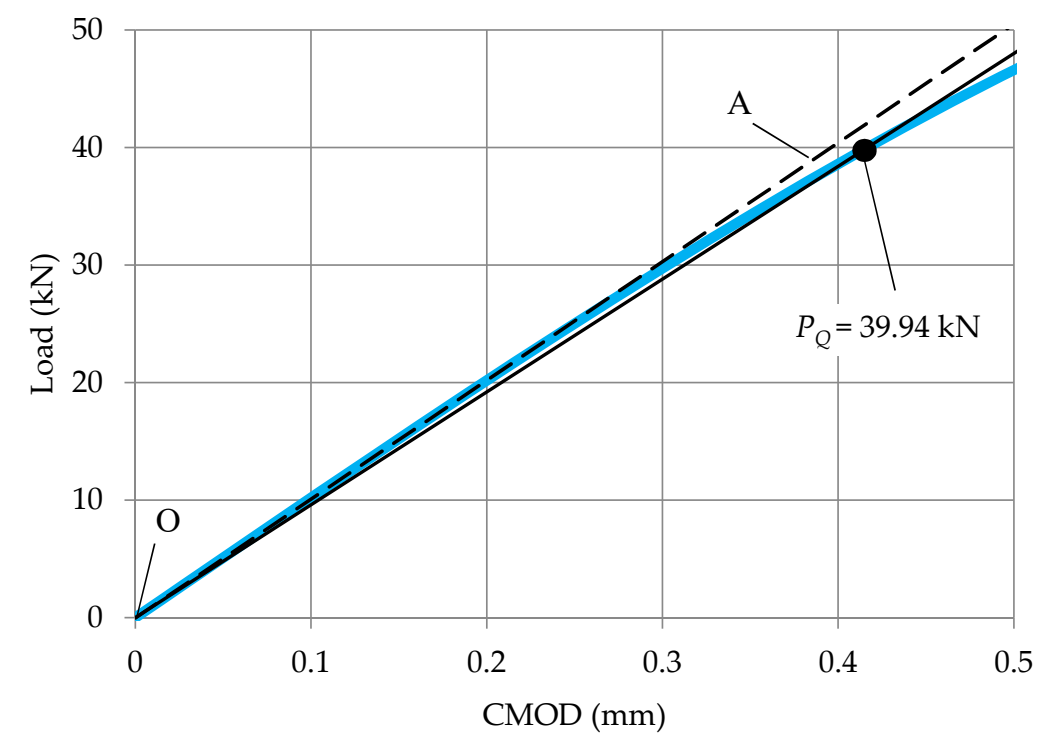

Figure 7. Determination of $P_{Q}$ load for the as-received specimen at room temperature.

The comparison of the analytically calculated stress intensity factor with the numerically simulated $K_{J}$ (see Figure 8) shows that at lower levels of loading $K_{J}$ is close to the analytically calculated stress intensity factor. However, in our case, it starts to deviate when the load reaches $30 \mathrm{kN}$. Also, the patterns of the curves are different: the numerically simulated curve is exponential while the analytically calculated curve is linear. It means that this stress intensity factor calculation approach can be used only at low loading levels. And as $P_{Q}$ load is around $40 \mathrm{kN}$ for the as-received and aged steel P91, this approach for numerical simulation of fracture toughness is not suitable.

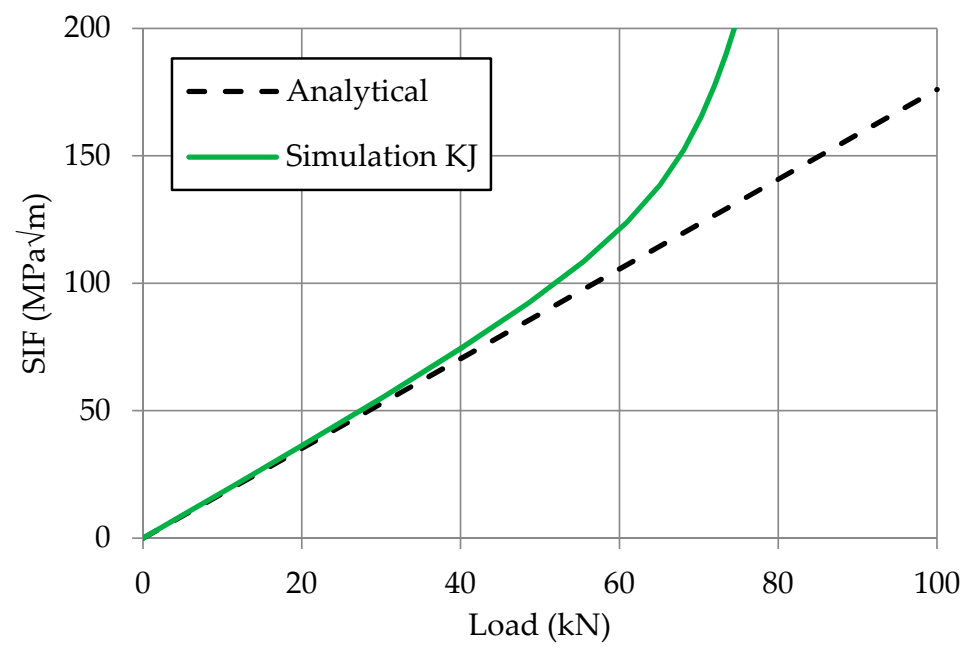

Figure 8. Comparison of $K_{J}$ with the analytically calculated stress intensity factor.

The other approach is direct calculation of the stress intensity factor by the procedures implemented in ABAQUS [17]. However, as the stress intensity factor is the parameter of linear fracture mechanics [1] it can be determined only by linear FE analysis [17]. Therefore, the second linear elastic specimen tension simulation has to be carried out, where only elastic material properties are used. Figure 9 shows that the direct stress intensity factor calculation does yield close results to the analytical approach. Numerically determined SIF values at load of $50 \mathrm{kN}$ deviate from the analytical results only up to $2 \%$. This small deviation was received due to the fact that the 3D FE model does evaluate strains in three directions and strains along the thickness of the specimen have a considerable effect on the specimen of $25 \mathrm{~mm}$ thickness. However, the ASTM E399 standard, where the equation for the analytical SIF 
calculation is described, presents a test procedure for plane-strain fracture toughness where strains along the thickness should be neglected.

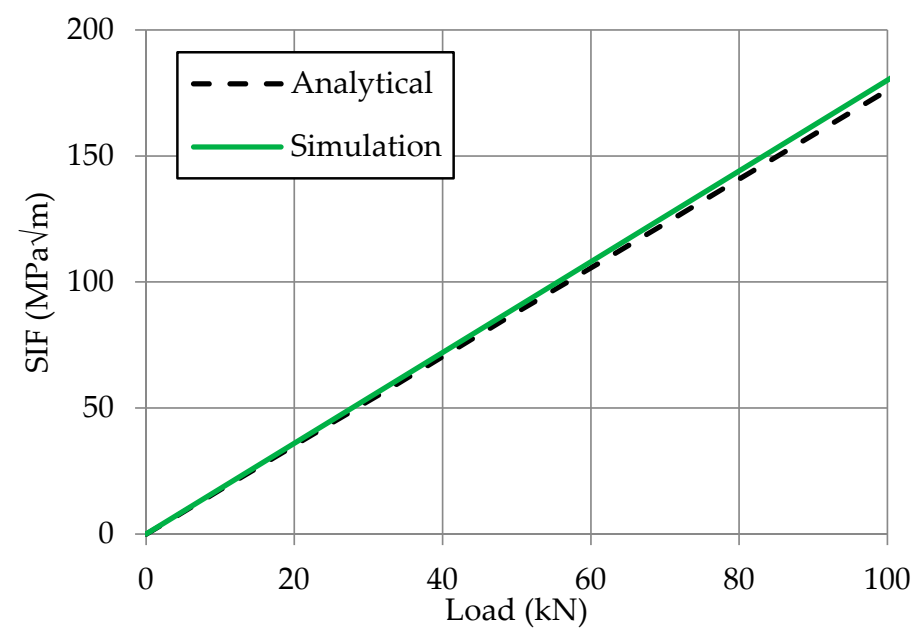

Figure 9. Stress intensity factor vs. load.

\section{Results and Discussion}

\subsection{Results of Experimental Research}

The averaged mechanical properties of the as-received and aged steel P91 determined experimentally are shown in Table 2.

Experimentally determined stress-strain curves of the as-received and aged steel P91 at room and elevated temperatures are presented in Figure 5. These curves were used for the description of material behaviour in the numerical model for fracture toughness simulation.

Experimentally determined fracture toughness results at room temperature are shown in Table 3.

Table 3. Averaged fracture toughness test results at room temperature for the as-received and aged P91 steel.

\begin{tabular}{ccccc}
\hline Ageing at $\mathbf{6 5 0} \mathbf{}^{\circ} \mathbf{C}(\mathbf{h})$ & $\boldsymbol{P}_{\mathbf{Q}} \mathbf{( k N )}$ & $\boldsymbol{P}_{\max }(\mathbf{k N})$ & $\boldsymbol{K}_{Q}(\mathbf{M P a} \sqrt{ } \mathbf{m})$ & $\boldsymbol{K}_{\max }(\mathbf{M P a} \sqrt{\mathbf{m}})$ \\
\hline 0 & 42.4 & 82.7 & 75.1 & 146.4 \\
790 & 41.4 & 81.3 & 73.4 & 143.5 \\
4150 & 41.9 & 78.0 & 73.9 & 137.5 \\
11,000 & 41.1 & 77.0 & 70.6 & 135.8 \\
\hline
\end{tabular}

\subsection{Results of Numerical Fracture Toughness Simulation}

The fracture toughness was investigated after a long-term exposure of P91 steel at $650{ }^{\circ} \mathrm{C}$ temperature. To evaluate the ageing impact on the fracture toughness of the P91 steel it was calculated for several specimens with different ageing time. The numerical simulation was carried out at room temperature and the determined results were compared with the experiment data. Numerically and experimentally determined $P_{Q}$ and $P_{\max }$ loads are presented in Figure 10. According to the data ageing of the steel does have an influence and the biggest effect is for the $P_{\max }$ load. The highest deviation of numerically simulated results comparing to the experiment data was up to $9 \%$ and it was received for the specimen aged for 11,000 h. In general, simulation results are in good agreement with the experiment. 


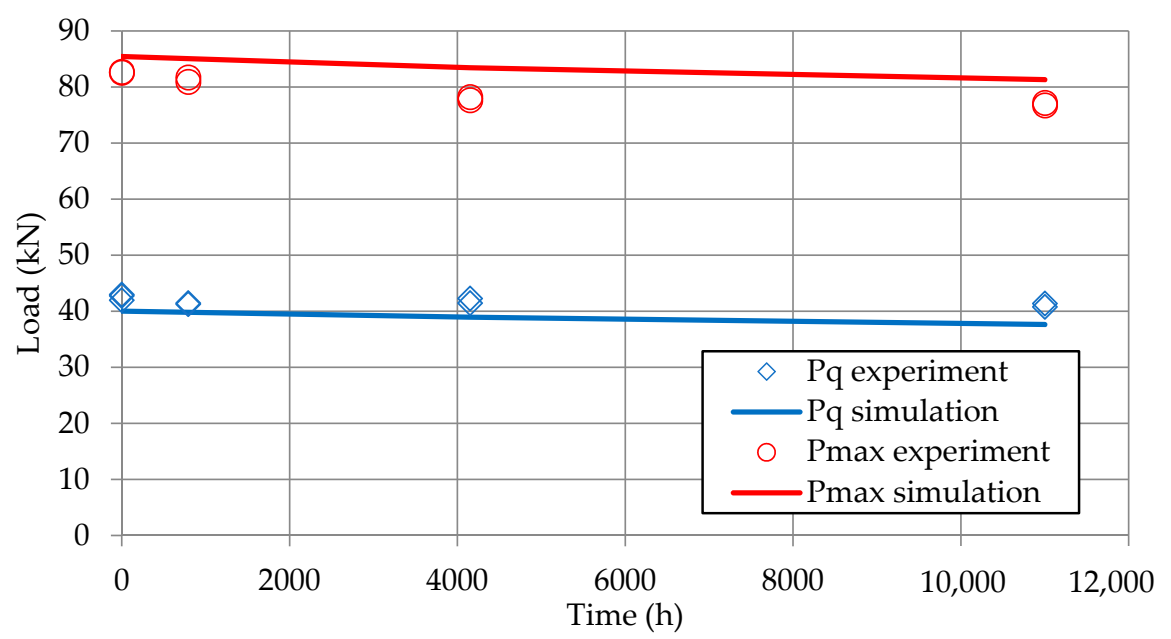

Figure 10. Numerically and experimentally determined $P_{Q}$ and $P_{\max }$ loads of steel $P 91$ at different ageing times.

Experimentally and numerically determined $K_{Q}$ and $K_{\max }$ values at room temperature for as-received and aged materials are presented in Figure 11. According to the figure, with an increase of the ageing time both fracture toughness values are decreasing. Comparing numerical and experimental results it can be seen, that at all ageing time points numerically determined $K_{Q}$ values are lower and $K_{\max }$ values are higher than experimentally determined values. However, the difference between numerical and experimental results is not large, where the highest deviation is less than $9 \%$. The decrease of fracture toughness after an ageing time of $11,000 \mathrm{~h}$ is not significant, where experimentally determined $K_{Q}$ and $K_{\max }$ values decreased respectively by $4 \%$ and $7 \%$ and numerically determined values decreased by $6 \%$ and $5 \%$.

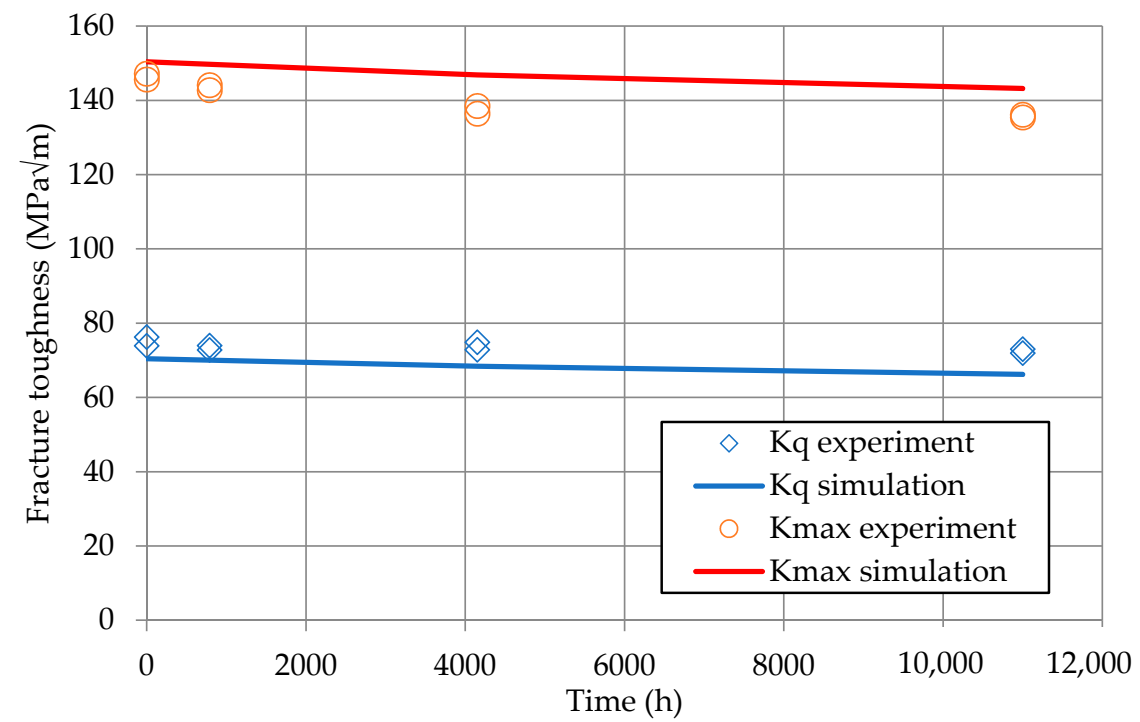

Figure 11. Numerically and experimentally determined fracture toughness values vs. ageing time of steel P91 at room temperature.

As the numerical simulation results of fracture toughness at room temperature have a good coincidence with experiment data, the numerical prediction of the fracture toughness at elevated temperature, i.e., $550{ }^{\circ} \mathrm{C}$, was carried out. Accordingly [18] the ageing time of steel can be recalculated into the IV generation nuclear reactor operation time regarding reactor design temperature. Hence, steel ageing time of $11,000 \mathrm{~h}$ at the $650^{\circ} \mathrm{C}$ temperature does correspond approximately to 60 years of operation in an IV generation nuclear reactor at $550^{\circ} \mathrm{C}$. 
Numerical simulation results of fracture toughness dependencies on ageing time at elevated temperature are presented in Figure 12. The influence of temperature in the fracture toughness determination was estimated using material properties determined at the given temperature, i.e., the $\mathrm{C}(\mathrm{T})$ specimen behaviour is described by the material properties determined at the elevated temperature. Also, it should be mentioned that the $P_{Q}$ load is determined to have close to a linear behaviour of $\mathrm{C}(\mathrm{T})$ specimen (the secant line $\mathrm{OP}_{5}$ only has a $5 \%$ slope) and for determination of the $P_{Q}$ load no crack growth or initiation modeling is needed. In order to be sure that numerical prognoses are accurate the experimental test for the as-received steel at elevated temperature have been carried out. The comparison shows that experimental and numerical results are close and do not deviate more than $6 \%$. This small deviation confirms that numerical prediction of fracture toughness at elevated temperature is accurate. According to the obtained results, the decrease of $K_{Q}$ and $K_{\max }$ values are respectively $18 \%$ and $6 \%$. However, as only one experimental test was done at higher temperature, the extended investigation on the difference of fracture mechanism, crack mouth opening and closure or crack mouth deformation could not be done reliably. Therefore, it cannot be stated with high confidence that the presented numerical methodology is suitable for fracture toughness determination at higher temperatures.

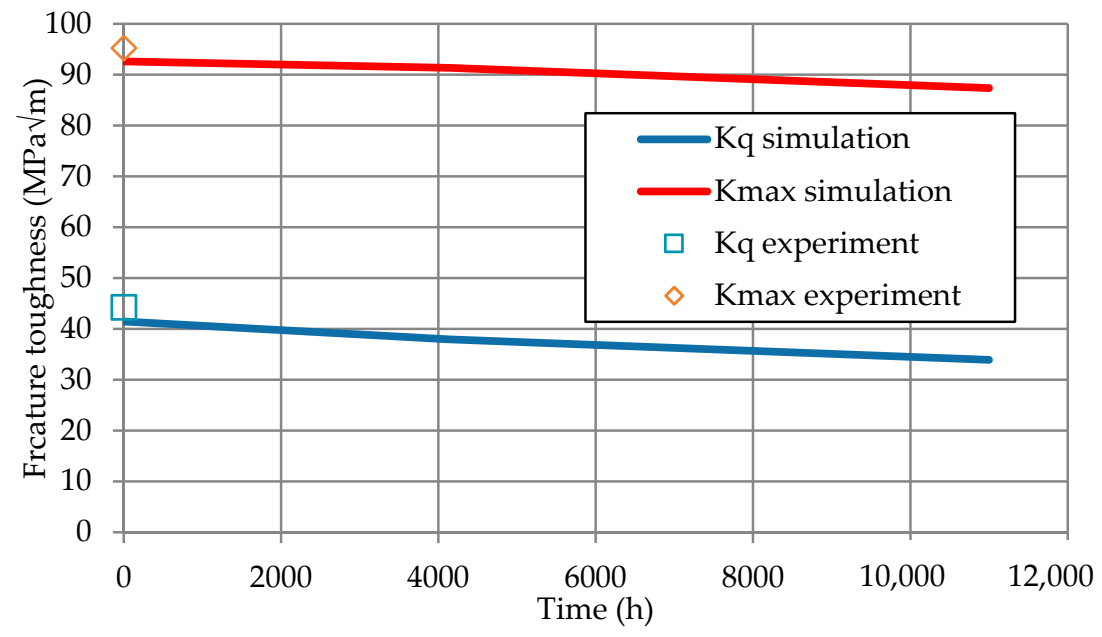

Figure 12. Numerically predicted fracture toughness values vs. ageing time of steel P91 at elevated temperature.

The study revealed that ageing process has an influence on mechanical properties as well as on fracture toughness of the steel P91. However, the decrease of $K_{Q}$ values for aged material at room temperature was not big. That shows a good resistance to thermal ageing of steel P91 which was confirmed by Baek et al. [19] and other researchers. Baek et al. estimated that the microhardness and strength of modified 9Cr-1Mo steel after long-term ageing at $600{ }^{\circ} \mathrm{C}$ for $50,000 \mathrm{~h}$ changed insignificantly. Researches determined that yield strength decreased by $28 \mathrm{MPa}$ (equiv. to $5 \%$ reduction) and the ultimate tensile strength decreased by $7 \mathrm{MPa}$ (equivalent to a $1 \%$ reduction) by comparing aged steel with that of the as-received one. Zieliński and Dobrzański [20] also confirms that ageing at $600{ }^{\circ} \mathrm{C}$ and $650{ }^{\circ} \mathrm{C}$ do not result in significant changes in mechanical properties. However, Cumino et al. [21] conducted an experiment for steel P91 where it was aged at 625 and $650{ }^{\circ} \mathrm{C}$ temperatures and they estimated a bigger influence to material properties. After experiments the authors concluded that tensile properties of steel P91 reduced by $10 \%$ after $1000 \mathrm{~h}$ of ageing. The authors claimed that after $3000 \mathrm{~h}$ of ageing the impact properties were reduced and brittle fracture was increased. Junek et al. [22] evaluated the mechanical properties and microstructures of similar and dissimilar welds of martensitic steels P91 and P92 after long-term laboratory ageing at elevated temperatures. The research of mechanical properties of base metals, i.e., steel P91 and P92, had similar results, i.e., insignificantly changes in mechanical properties. The ultimate strength of aged metals even up to 30,000 h had no 
significant decrease (approx. $20 \mathrm{MPa}$ ) when the ageing temperature was $650{ }^{\circ} \mathrm{C}$. However, the ageing effect was strong at an ageing temperature of $700{ }^{\circ} \mathrm{C}$. Here ultimate strength of steel P91 decreased by $95 \mathrm{MPa}$. In our study the ageing effect is evaluated by application of material properties of the aged steel in the FE model. Consistent with the findings that aged material properties (see Table 2) have changed insignificantly the decrease of fracture toughness for aged material was also small. Current research revealed that $K_{Q}$ values at room temperature decreased only up to $4 \%$ determined experimentally and $6 \%$ determined numerically.

\section{Conclusions}

This research covers the presentation and validation of a numerical method for the fracture toughness determination and evaluation of ageing influence on the fracture toughness of steel P91.

Numerical simulation was done by running non-linear and linear tension simulations of $C(T)$ specimen. Non-linear simulation was used for $P_{Q}$ and $P_{\max }$ load determination while linear simulation was used for determination of $K_{Q}$ and $K_{\max }$. To validate the numerical 3D FE model for fracture toughness analysis the numerical simulation results were compared to the experimental data.

Experimental tests showed that after long time exposure at $650{ }^{\circ} \mathrm{C}$ the mechanical properties of steel P91 decreased. However, the change of tensile and yield strength after ageing for 11,000 $\mathrm{h}$ was relatively small and did not exceed $5 \%$. Fracture toughness test results showed that $K_{Q}$ and $K_{\max }$ values also had a small decrease. The highest decrease was for the $K_{\max }$ value and it reached $7 \%$.

Numerical simulation of ageing influence on fracture toughness of steel P91 was carried out at room and elevated temperature $\left(550^{\circ} \mathrm{C}\right)$. The comparison of the numerically determined fracture toughness results with the experimental results show a good coincidence which demonstrates the suitability of the numerical simulation method for fracture toughness determination at room temperature.

Experimental testing and numerical simulation results obtained in this study show that steel P91 has good resistance to thermal ageing and still has high ductility even after long thermal exposure $\left(11,000 \mathrm{~h}\right.$ at $\left.650{ }^{\circ} \mathrm{C}\right)$.

Author Contributions: Conceptualization, G.D. and R.J.; methodology, G.D., R.J. and A.G.; experiment, A.G.; numerical simulation, R.J.; data curation, A.G.; result analysis, G.D., R.J. and A.G., writing-original draft, G.D., R.J. and A.G.; writing-review \& editing, G.D., R.J. and A.G.; visualization, R.J.; supervision, G.D. All authors have read and agreed to the published version of the manuscript.

Funding: This research received no external funding.

Conflicts of Interest: The authors declare no conflict of interest.

\section{References}

1. Anderson, T.L. Fracture Mechanics, Fundamentals and Applications; CRC Press Inc.: Boca Raton, FL, USA; Ann Arbor, MI, USA; Boston, MA, USA, 1991; 793p, ISBN 0-8493-4277-5.

2. Zare, A.; Kosari, E.S.M.; Asadi, I.; Bigham, A.; Bigham, Y. Finite element method analysis of stress intensity factor in different edge crack positions, and predicting their correlation using neural network method. Res. J. Recent Sci. 2014, 3, 69-73.

3. Peiyuan, L.; Li, C.; Xiaojun, Y.; Dawei, H.; Xiaoyu, Q.; Xiaoyong, Z. A temperature-dependent model for predicting the fracture toughness of superalloys at elevated temperature. Theor. Appl. Fract. Mec. 2018, 93, 311-318. [CrossRef]

4. Sakib, A.R.N.; Adnan, A. On the size-dependent critical stress intensity factor of confined brittle nanofilms. Eng. Fract. Mech. 2012, 86, 13-22. [CrossRef]

5. Mohsin, N.R. Comparison between theoretical and numerical solutions for center, single edge and double edge cracked finite element plate subjected to tension stress. Int. J. Mech. Prod. Eng. Res. Dev. 2015, 5, 11-20.

6. Kacianauskas, R.; Zenon, M.; Zarnovskij, V.; Stupak, E. Three-dimensional correction of the stress intensity factor for plate with a notch. Int. J. Fract. 2005, 136, 75-98. [CrossRef]

7. Silva, F.J.G.; Pinho, A.P.; Pereira, A.B.; Paiva, O.C. Evaluation of welded joints in P91 steel under different heat-treatment conditions. Metals 2020, 10, 99. [CrossRef] 
8. Blinn, B.; Görzen, D.; Fischer, T.; Kuhn, B.; Beck, T. Analysis of the thermomechanical fatigue behavior of fully ferritic high chromium steel Crofer@22 H with cyclic indentation testing. Appl. Sci. 2020, 10, 6461. [CrossRef]

9. Yang, K.; Zhang, Y.; Zhao, J. Elastoplastic fracture analysis of the P91 steel welded joint under repair welding thermal shock based on XFEM. Metals 2020, 10, 1285. [CrossRef]

10. Bertrand, F.; Marie, N.; Bachrata, A.; Brun-Magaud, V.; Droin, J.B.; Manchon, X.; Herbreteau, K.; Farges, B.; Carluec, B.; Poumerouly, S.; et al. Status of severe accident studies at the end of the conceptual design of ASTRID: Feedback on mitigation features. Nucl. Eng. Des. 2018, 326, 55-64. [CrossRef]

11. Sasikala, G.; Ray, S.K.; Mannan, S.L. Kinetics of transformation of delta ferrite during creep in a type 316(N) stainless steel weld metal. Mater. Sci. Eng. A 2003, 359, 86-90. [CrossRef]

12. Thomas Paul, V.; Saroja, S.; Vijayalakshmi, M. Microstructural stability of modified 9Cr-1Mo steel during long term exposures at elevated temperatures. J. Nucl. Mater. 2008, 378, 273-281. [CrossRef]

13. Baltušnikas, A.; Lukošiūtè, I.; Makarevičius, V.; Kriūkienè, R.; Grybènas, A. Influence of thermal exposure on structural changes of M23C6 carbide in P91 steel. J. Mater. Eng. Perform. 2016, 25, 1945-1951. [CrossRef]

14. ISO 6892-1 Metallic Materials-Tensile Testing-Part 1: Method of Test at Room Temperature; European Committee for Standardization: Brussels, Belgium, 2009.

15. ISO 6892-2 Metallic Materials-Tensile Testing-Part 2: Method of Test at Elevated Temperature; European Committee for Standardization: Brussels, Belgium, 2011.

16. ASTM E399-12e3 Standard Test Method for Linear-Elastic Plane-Strain Fracture Toughness KIc of Metallic Materials; ASTM International: West Conshohocken, PA, USA, 2012.

17. ABAQUS/Standard User's Manual, Version 6.11. 2011. Available online: http://130.149.89.49:2080/v6.11/ index.html (accessed on 10 December 2020).

18. Grybėnas, A.; Makarevičius, V.; Baltušnikas, A.; Lukošiūtė, I.; Kriūkienė, R. Correlation between structural changes of M23C6 carbide and mechanical behaviour of P91 steel after thermal aging. Mat. Sci. Eng. A Struct. 2017, 696, 453-460. [CrossRef]

19. Baek, J.H.; Kim, S.H.; Lee, C.B.; Hahn, D.H. Mechanical properties and microstructural evolution of modified 9Cr-1Mo steel after long-term ageing for 50,000 h. Met. Mater. Int. 2009, 15, 565-573. [CrossRef]

20. Zieliński, A.; Dobrzański, J. Characteristics of changes in properties and structure of X10CrMoVNb9-1 steel due to long-term impact of temperature and stress. Arch. Mater. Sci. 2013, 60, 72-78.

21. Cumino, G.; Di Cuonzo, S.; Di Gianfrancesco, A.; Tassa, O. Advanced high chromium ferritic steels for boiler components operating at high temperature. Lat. Am. Appl. Res. 2002, 32, 229-235.

22. Junek, M.; Svobodova, M.; Janovec, J.; Horvath, J.; Duchacek, P. Long-term thermal degradation of narrow gap orbital welded P91 and P92 steels. Int. J. Press. Vessels Pip. 2020, 185, 104133. [CrossRef]

Publisher's Note: MDPI stays neutral with regard to jurisdictional claims in published maps and institutional affiliations.

(C) 2020 by the authors. Licensee MDPI, Basel, Switzerland. This article is an open access article distributed under the terms and conditions of the Creative Commons Attribution (CC BY) license (http://creativecommons.org/licenses/by/4.0/). 